\title{
UM COMERCIANTE DO CICLO DO AÇƯCAR PAULISTA: ANTÔNIO DA SILVA PRADO (1817-1829) (III).
}

\section{(Conclusão) .}

\section{MARIA TEREZA SCHORER PETRONE}

Professôra-assistente da Cadeira de Histórla da Civillzação Brasileira da Faculdade de Filosofia, Ciências e Letras da Untversidade de Sáo Paulo.

\section{* \\ VI). - Remessas para outros portos.}

Além dos negócios com a Bahia e o Rio de Janeiro, Antônio da Silva Prado também mantinha relações mercantís com portos do Sul, tanto nacionais como platinos. Sem ser um comércio importante, não deixa de ter alguma significação, principalmente, porque mostra alguns pormenores das relações entre Santos e essas áreas. Esse comércio não é feito, entretanto, nas mesmas bases do que se realizava com o Rio ou a Bahia. O açúcar não ia por conta do comerciante a um correspondente incumbido de vendê-lo. Geralmente era mandado a um barco destinado ao Sul ou, então, a um comerciante vindo a Santos especialmente para adquirir açúcar. Não encontramos o mínimo indício de correspondência com aquêles portos.

Em abril de 1819, Prado estava disposto a ceder uma porção de açúcar a ser carregado para Pôrto Alegre em troca de letras que se descontariam no Rio de Janeiro. Em setembro de 1819, vendeu 400 arrôbas a um indivíduo que ia a Pôrto Alegre ou ao Rio Grande (343). Na mesma época, vendeu 500 arrôbas em sacos a um tropeiro do Sul que queria conduzir pessoalmente o açúcar também para Pôrtor Alegre ou Rio Grande (344). A venda efetuou-se em São Paulo e Prado recebeu imediatamente a importância correspondente ao açúcar e às despesas em Santos. O branco saiu a 1.920 réis a arrôba e o redondo a 1.600 , postos a bordo de uma embarcação. Proost ficou encarregado de tratar do embarque do açúcar e da pas-

(343). - Idem., 19, f. 134 vs., 7 de setembro de 1819.

(344). - Ibidem. 
sagem do comprador. Ao que se deduz dessas cartas, as viagens de Santos a Pôrto Alegre ou Rio Grande não deviam ser muito freqüentes; as embarcações ficavam muito tempo em Santos a espera de carga para aquêles pôrtos.

Parece que Proost conseguiu, certa ocasião, que the consignassem uma embarcação do Rio Grande para a qual pretendia negociar açúcar de Antônio da Silva Prado (345) . Em agôsto de 1819, também conseguiu vender todo o açúcar redondo para o caixa de uma embarcação de Santa Catarina. Embora não se possa perceber a quantidade de açúcar empregado na transação, o fato é que Antônio da Silva Prado se mostrou contente com a "venda de alguas porções pa o Rio Grande e Sta Catarina e posto q não tivesse lucro nestes contudo como não tive prejuízo foi fortuna pa o estado presente" (346) .

Em fevereiror de 1820 , aparece um freguês que quer comprar 1.500 arrôbas, a serem embarcadas para o Rio Grande. Antônio da Silva Prado dispõe em Santos de pouco açúcar e pede, então, a Proost que the complete a quantidade (347). Na safra de 1820-1821 pediu a um intermediário que apressasse a remessa de açúcar para Santos, pois queria enviá-lo ao Rio Grande (348). Ao mesmo tempo, pede a Proost que aprontasse uma remessa com igual destino (349). Em 1820 , vendeu também açúcar para embarcações que se dirigiam a Laguna e Santa Catarina (350). Em 1821, pede o comerciante a Proost para verificar se "havia algum navio pa Porto Alegre pois tenho intento de embarcar pa aquele Portro parte do meo assucar qdo não consiga vende-lo ahi” (351) .

A correspondência revela que, em 1820, embarcações de Montevideu e Buenos Aires vieram a Santos buscarr açúcar (352). Não se consegue saber, entretanto, se êle próprio fêz remessas por essas embarcações. Em setembro de 1820, pede a Proost que verifique a possibilidade de vender açúcar a um comprador de Buenos Aires: "o sugeito que tem embarcação fretada pa Buenos Airres, volta pa essa e vai ahi comprar assucar visto q o não pode fazer nesta" (353).

Nas suas cartas também faz referências ao comércio com a Metrópole. Em fins de 1819, conta a Proost que, pelo correio, rece-

\footnotetext{
(345). - Idem., 19, f. 159, 23 de outubro de 1819.

(346). - Idem., 19, f. 145 vs., 11 de outubro de 1819.

(347). - Idem., 19, f. 188, 1 de fevereiro de 1819.

(348). - Idem., 19, f. 267, 9 de agôsto de $1820 ; 19$, f. 270,16 de agôsto de 1820.

(349) . - Idem., 19, 1. 277 vs., 30 de agôsto de 1820. Parece tratar-se de uma embarcaçăo consignada a Proost, pois, Antônio da Stlva Prado, fala... "pa mdar pa o Rio Grd qdo for a sua Embarcaçăo".

(350) . - Idem., 19, f. 270, 16 de agôsto de 1820; 19, f. 256, 12 de julho de 1820 .

(351). - Idem., 20, f. 118,8 de novembro de 1821 .

(352) . - Idem., 19, f. 204, 12 de março de 1820.

(353) . - Idem., 19, f. 298, vs., 11 de outubro de 1820.
} 
bera notícias da Bahia sôbre a chegada de quatro navios de Lisboa, dando "as peiores noticias a respeito do comercio". Certa pessoa lhe dissera o mesmo, acrescentando que não convinha embarcar produtos para o Pôrto (354). Outra queria que êle enviasse açúcar ao Pôrto para receber em São Paulo o dinheiro, mas Prado não quis saber do negócio, pois "isso he dar mel pelos beiços e ao depois vir a conta de venda com grande prejuizo, pr isso nem fallar em similhante negocio" (355).

Mais tarde, resulveu mandar cinco caixas de açúcar a Lisboa, consignadas ao pai de um amigo. Não tinha mudado de idéia quanto ao comércio com Portugal. A remessa de açúcar era uma forma de poder dispor no Reino de recursos para pagar certas encomendas (um lustre e quatro colchas de damasco) (356). Tratava-se, portanto, de um negócio semelhante a outros que fizera na Bahia. Deve ter mandado mais algum açúcar com o mesmo destino. A seu irmão, estabelecido em Caiteté, informa que tem em Lisboa dezessete caixas de açúcar "em q hei de soffrer não pequeno prejuizo" (357). No fim do ano conta, ainda em Lisboa, com vinte caixas (358).

Vê-se que as remessas para Portugal não tinham grande importância, outro tanto acontecendo com as que se destinavam aos portos do Sul. E verdade que também para a Bahia não mandou muito açúcar, mas as remessas, nesse caso, davam certo lucro, graças às mercadorias que lhe permitiam comprar. A maior parte do açúcar foi para o Rio de Janeiro, principalmente nos primeiros anos. Depois preferia vendê-lo em Santos.

Como na correspondência estudada há um hiato entre 1822 e 1825 , não podemos perceber o rumo tomado por êsses negócios de açúcar (359). Recomeçando em 1825 e indo até 1829, as cartas mostram que o interêsse por essa atividade quase desaparecera. $\mathrm{Pa}-$ rece que só ocasionalmente se ocupou dêles. Seu maior interêsse, certamente, sua maior fonte de renda, é a arrematação de rendas públicas, à cuja cobrança faz constantes referências. Desde sua volta a São Paulo, dedicara-se a êsse ramo. Ele e alguns sócios, entre os quais Manuel Moreira Lírio, arremataram o contrato de diversas

(354). - Idem., 19, f. 159 vs., 23 de outubro de 1819.

(355). - Idem., 19, f. 221, 25 de abril de 1820 .

(356). - Idem., 19, f. 224,4 de malo de 1820 .

(357). - Idem., 19, f. 227, 8 de maio de 1820 .

(358) - - Idem., 19, f. 328 vs., 21 de dezembro de 1820

(359). - O 49 copiador de cartas extraviou-se. Praticamente, desde fins de 1821, năo há mais referências sôbre a evolução de seus negócios de açúcar. 
rendas públicas, tais como a siza, o nôvo impôsto, o subsídio literário, a meia siza, o banco, etc. Como em São Paulo, naquela época, a riqueza dependia essêncialmente da lavoura canavieira a maior ou menor renda dêsses tributos dependia do progresso dessa cultura. Informando, por exemplo, Lírio e seus irmãos sôbre as vantagens da arrematação de alguns ramos dos dízimos da Capitania, mostra-se, em dado momento, inquieto por ter "havido geada $\mathrm{q}$ destruio mtos canaviaes" (360). Em outra ocasião, tendo arrematado os dízimos de São Sebastião, espera uma boa safra (361) .

Há uma série de referências à ida de aguardente e açúcar de São Sebastião ao Rio, como pagamento de dízimo (362). O pagamento das taxas girava em tôrno da safra, boa ou má. Mas de certa feita explicava a um cobrador de Itú que "a Fazde Real exige de mim o pagamento com velocidade" ... "e pouco me importa q tenhão vendido ou não as safras" (363). Nos anos em que mais intensamente se interessou pelo açúcar são raras, porém, as informações que permitam supor uma ligação entre essa atividade e a cobrança das rendas públicas. Mas de 1825 a 1829 , percebemos que quase todos os negócios de açúcar são decorrência da arrecadação da cobrança de rendas pública. Trrata-se quase sempre de açúcar recebido em pagamento de determinada taxa. Assim, uma das primeiras referências a açúcar na correspondência de 1825 , figura em carta a um cobrador em Itú, aconselhando-o a fazer a cobrança: "Quanto ao q se me deve de Sizas bom seria vm" ver se consegue obrgm dos devedorez em q prometão pagar-me na próxima safra de assucar, ou dro attendendo qmmo em assucar me faz conta receber, em este genero não serão penozos os pagamentos" (364).

Em 1825, mantinha com Proost as mesmas relações do período anterior e êste ao que parece, comprava todo o açúcar que Antônio da Silva Prado recebia pelas taxas. Ao correspondente em Santos escrevia: "O assucar que receber de próximo hé o último que tenho, pois nem neste genero me foi possivel cobrar alga coiza do que se me deve apezar das diligencias" (365). Não recebeu, porém, muito açúcar em pagamento. Em fins de abril de 1825 , escrevia a Proost que lhe debitava 92\$200 réis "importancia de 109 arrobas de assucar, $\mathrm{q} \mathrm{pr} \cdot \mathrm{s} / \mathrm{c}$ lhe remetti a safra finda, sendo este todo o q pude receber

\footnotetext{
(360). - Idem., 18, ค. 120 vs.; 20 de junho de 1818.

(361). - Idem., 18, f. 131 vs., 21 de Junho de 1818.

(362). - Idem., 19, f. 152 vs., 14 de novembro de 1819; 20, f. 113, 23 de outubro de $1821 ; 20$, f. 133 vs., etc.

(363). - Idem., 19, f. 219, 16 de abril de 1820.

(364). - Idem., 21, f. 15 vs., 8 de março de 1825 .

(365). - Idem., 21, f. 22 vs., 23 de março de 1825.
} 
em pagamento do q me devem os Srs Engenhros" (366) . Não fica bem claro se recebeu sòmente essa quantidade, mas, em todo caso, não seria muito. Logo em seguida, prometia a Proost todo o açúcar da safra futura que eventualmente recebesse em pagamento (367). No comêço da safra, porém, avisa que provàvelmente iria pouco açúcar (368).

O recebimento das taxas dependia da venda da safra pelo senhor de engenho. Este, é o que se pode deduzir, preferia negociar o açúcar por conta própria a dá-lo em pagamento de taxas, pois, assim, obteria preços maiores do que os vigentes para o açúcar no engenho. Assim, por exemplo, um senhor de engenho de Pôrto Feliz enviou seu açúcar ao Rio de Janeiro e Antônio da Silva Prado esperava que êle saldasse sua dívida logo que o vendesse (369). Em outra ocasião, esperava que os senhores de engenho saldassem as dívidas logo que recebessem o correspondente à safra vendida (370). Outro proprietário enviou o açúcar para Santos incumbindo a Proost de vendê-lo. E Antônio da Silva Prado aconselhava que o fizesse ràpidamente, pois o mesmo proprietário "acha-se atrazado commigo, e este assucar hé pa meo pagamento" (371).

Vê-se, portanto, que em 1825 todo o interêsse pelo açúcar se prendia às cobranças de impostos ou talvez de outras dívidas. Ao que parece, Antônio da Silva Prado abandonara inteiramente o comércio de açúcar. Só vendia o resultante de pagamentos de taxas dos contratos. Proost, que antes beneficiava seu açúcar, agora é o comprador e vendedor do produto oriundo de tais fontes.

Em 1826, as referências ainda são mais raras ao açúcar. Em setembro, informa ao correspondente que lhe enviava 254 arrôbas de açúcar "certo de que o venderá como seu", para, logo em seguida, aconselhá-lo a que o remeta para o Rio, pois lá era vendido com maior rapidez, tanto mais quanto "o seu producto hé pa mim pagamento" (372). Parece que outras remessas para o Rio de Janeiro foram feitas por conta de Proost, mas, o lucro da venda devia pertencer a Prado (373). Também no ano seguinte, Prado encarregou o correspondente da venda de açúcares recebidos em pagamento. Proost enviava-o por sua conta ao Rio e a renda cabia ao negociante

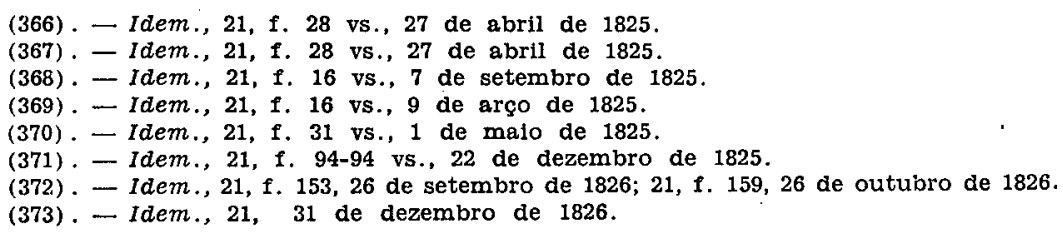


(374). Em 1828, todo o açúcar negociado também provém de dívida de contribuintes. Em janeiro, pede o pagamento de uma dívida, anunciado para a ocasião da safra (375). Em Piracicaba, um senhor de engenho tinha prometido certa quantidade de açúcar em pagamento da siza. Como a remessa demorasse, Antônio da Silva Prado pede que, caso o tivesse vendido, pelo menos mandasse o dinheiro (376). Outro, não podia pagar a dívida porque seu canavial fôra destruído pelo fogo (377.) . Certo proprietário enviou o açúcar para ser vendido em Santos por Proost e dessa maneira queria pagar (378). Parece que apesar de tudo, Antônio da Silva Prado ainda deve ter enviado algum açúcar ao Rio de Janeiro, pois em junho recebeu uma letra pela venda ao "ingles" (379). Proost comprou-lhe açúcar no valor de $223 \$ 200$ réis, em dezembro de 1828 (380). Nesse ano, também os negócios com açúcar não deviam estar muito bons, pois Proost, que fizera vultuosa compra, "esta com medo de perder este anno grda parte de q ganhou o passado" (381).

$\mathrm{Na}$ realidade, as referências se vão fazendo cada vez mais raras . O açúcar só é mencionado esporàdicamente. Aos poucos desaparecem também as referências ao recebimento dêsse gênero em pagamento de taxas. Em agôsto de 1829, o futuro barão de Iguape explica o fato a Proost dizendo: "Poucos devedores Engenhros tenho, e esses não me pagão pr forma algua, pr tanto não poderei arranjar assucar algm pr tendo elles qm lhes compre dinho não se sugeitão a dar em pagamto, como tem acontecido" (382).

Curioso é que na correspondência a Antônio da Silva Prado não há quase referências ao café que, naqueles anos, estava fazendo progressos no planalto. Em 1819, escrevia ao correspondente no Rio de Janeiro: "A vista das suas reflexões respeito ao café tenho assentado desprezar tal espiculação e só tentarei em porção mto limitada e pr

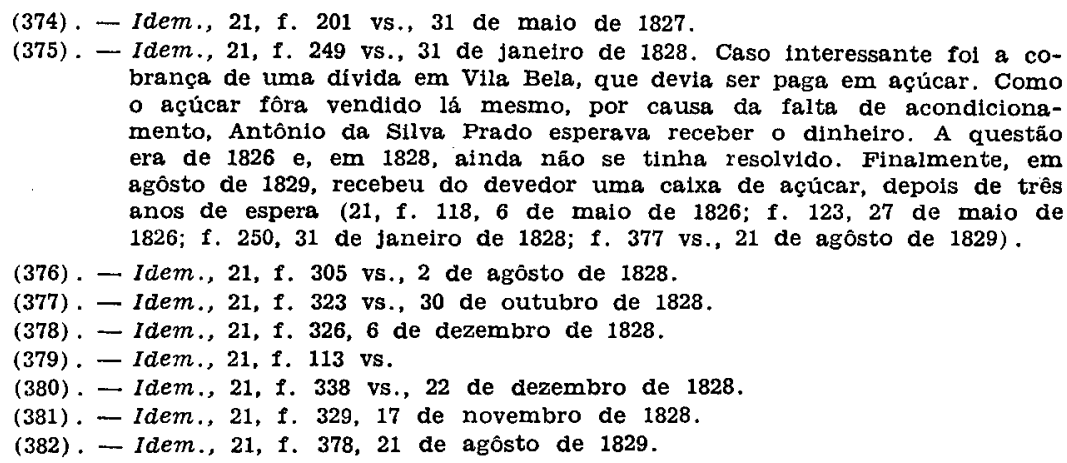
brança de uma dívida em Vila Bela, que devia ser paga em açúcar. Como - açúcar fôra vendido lá mesmo, por causa da falta de acondicionamento, Antônio da Sulva Prado esperava receber o dinheiro. A questão era de 1826 e, em 1828, ainda não se tinha resolvido. Finalmente, em agôsto de 1829, recebeu do devedor uma calxa de açúcar, depois de três anos de espera (21, f. 118,6 de malo de 1826; f. 123, 27 de maío de 1826; f. 250,31 de janeiro de $1828 ;$ f. 377 vs., 21 de agôsto de 1829).

(376) . - Idem., 21, f. 305 vs., 2 de agôsto de 1828.

(377). - Idem., 21, f. 323 vs., 30 de outubro de 1828 .

(378). - Idem., 21, f. 326, 6 de dezembro de 1828 .

(379). - Idem., 21, f. 113 vs.

(380). - Idem., 21, 1 . 338 vs., 22 de dezembro de 1828.

(381). - Idem., 21, f. 329, 17 de novembro de 1828 .

(382). - Idem., 21, f. 378, 21 de agôsto de 1829 . 
preço q convide" (383). Não parecia muito otimista àcêrca das possibilidades que o comércio dêsse produto podia oferecer. Pela correspondência pode-se ver que não se interessou por êle antes de 1825 , quando encontramos a primeira referência a uma remessa de 18 arrôbas para o Rio de Janeiro (384). Em 1828, esperava a venda do café enviado ao Rio por um devedor de Lorena, para que a dívida fôsse amortizada (385). São essas as únicas notícias sôbre negócio de café do futuro Barão de Iguape, que se encontram nas cartas.

Antônio da Silva Prado foi, sem dúvida, um grande homem de negócios de açúcar, comprovam-no as suas remessas de mais de 18.000 ou 20.000 arrôbas de açúcar para o Rio de Janeiro. Nos primeiros anos manteve, ao lado do comércio de açúcar, a arrematação da cobrança de rendas públicas. Percebe-se à leitura das cartas que ambas as atividades lhe interessam. Com o correr dos anos prefere, porém, dedicar-se à cobrança dos impostos, de maneira que, entre 1825 a 1829 , pouco se fala nos seus papéis sôbre o comércio de açúcar. Responsável por essa transformação é a situação econômica de São Paulo, do Rio de Janeiro, do país inteiro que com a emancipação, e mesmo já antes, ia sofrendo sensível alteração em sua estrutura. A cobrança de impostos era um negócio mais seguro para quem tivesse algum capital, embora o rendimento, bom ou mau, também dependesse da conjuntura econômica.

Para finalizar, transcrevemos um trecho de carta a seu irmão que negociava em Caiteté e pretendia transferir-se para São Paulo: "O estado actual do comercio nesta hé desgraçado, pr q tenho eu feito o anno passado, e este o empate de mais de 40:000\$000 em assucar me acho com hum empate extraordinro, e com ms de trez mil as em ser, q ja o dou com 700 rs de prejuizo em cada huma arroba, e mandei pa Lixa 17 Caixas em q ei de soffrer não pequenos prejuizos e de mais o giro de negocio nessa he mto ms suave, o $q$ não acontece nesta q cuidando encontraria meo sucego, he qdo não me chega o tempo pa dar Solução dos negocios q tenho a meo cargo, e apezar de q tenhão sido interessantes pela comissão q tenho annual, com tudo não me faltão dezos de me ver livre de sime lida o q penço conseguirei pa o futuro visto $q \mathrm{j}$ a tenho entrado pa o Banco com 8:000\$000 logo que posso ter alli mais fundos terei hu rendimento solido e sem trabalho" (386).

(383). - Idem., 19, P. 117, 21 de julho de 1819.

(384). - Idem., 21, f. 247, 7 de dezembro de 1825 .

(385). - Idem., 21, f. 206, 4 de agôsto de 1828.

(386) . - Idem., 19, f. 227, 8 de maio de 1820 . 